\title{
LA PARTICIPACIÓN FEMENINA EN LOS SITIOS DE ZARAGOZA. LA PERCEPCIÓN DEL MANDO MILITAR Y EL INTERÉS DEL PODER POLÍTICO
}

\author{
FEMALE PARTICIPATION IN THE SIEGES OF \\ ZARAGOZA. THE PERCEPTION OF THE MILITARY \\ COMMAND AND THE INTEREST OF POLITICAL \\ POWER
}

Francisco Ramiro Moya

Universidad de Zaragoza

\section{RESUMEN}

Este artículo estudia el papel desarrollado por las mujeres combatientes en los Sitios de Zaragoza durante la Guerra de la Independencia; el tipo de acciones en las que tomaron parte, sus oportunidades para salir del anonimato y su sufrimiento durante y después de la contienda. Además, atiende a los diferentes intereses de la movilización femenina durante la batalla y a la posterior imagen de las heroínas zaragozanas, indagando acerca de las motivaciones de las propias protagonistas, de los mandos militares de la plaza y del poder político que, tras la guerra, afrontó la labor de construcción del estado liberal. Palabras clave: Guerra de la Independencia, Sitios de Zaragoza, mujeres combatientes, historia de las mujeres.

\begin{abstract}
This article studies women's role in the Sieges of Zaragoza during the Peninsular War; the kind of actions in which they participated, their opportunities to lose their anonymity, and their suffering during and after the war. Moreover, it deals with the different interests of the female mobilization during the battle and the subsequent image of Zaragoza's heroines, examining the motivation of the protagonists, the military commanders and the politicians who, after the war, had to construct the liberal state.
\end{abstract}

Keywords: Peninsular War, Sieges of Zaragoza, Women Fighters, Women History. 


\section{RESUM}

\section{LA PARTICIPACIÓ FEMENINA ALS SETGES DE SARAGOSSA. LA PERCEPCIÓ DEL COMANDAMENT MILITAR I L'INTERĖS DEL PODER POLÍTIC}

Aquest article estudia el paper desenvolupat per les dones combatents als Setges de Saragossa durant la Guerra de la Independència; el tipus d'accions en les quals van prendre part, les seues oportunitats per eixir de l'anonimat i el patiment durant i després de la contesa. A més, atén als diferents interessos de la mobilització femenina durant la batalla i a la posterior imatge de les heroïnes saragossanes, indagant al voltant de les motivacions de les mateixes protagonistes, dels comandaments militars de la plaça i del poder polític que, després de la guerra, va afrontar la construcció de l'estat lliberal.

Paraules clau: Guerra de la Independència, Setges de Saragossa, dones combatents, història de les dones. 
Los primeros años del siglo XIX estuvieron marcados en el Viejo Continente por los afanes expansionistas del general francés Napoleón Bonaparte, quien trató de exportar las ideas de la Revolución surgida en el país galo al resto de territorios europeos, y de paso, dominarlos.

En el complejo contexto que había sacudido desde finales de 1789 a su vecino del norte, la monarquía hispana jugó un papel ambivalente, como aliado o enemigo de Francia, en función del cariz que tomaban los acontecimientos en el territorio galo. Fruto del tratado de Fontainebleau, que acordaba la invasión hispano francesa de Portugal, tradicional aliado británico, los Ejércitos napoleónicos entraron en la Península y, en su camino hacia el hostil territorio luso, fueron estableciéndose en diferentes ciudades y plazas fuertes estratégicas hispanas.

Cuando los incidentes entre las tropas extranjeras y la población hispana y la inestabilidad política surgida por la debilidad de la monarquía ante las pretensiones del Emperador provocaron el levantamiento de diversas poblaciones contra los invasores, Aragón y su capital, tradicionalmente recelosos hacia sus fronterizos vecinos meridionales, mantuvieron una actitud de abierta hostilidad hacia los Ejércitos franceses. Fruto de ese posicionamiento fueron los dos Sitios que entre junio y agosto de 1808 y diciembre de ese mismo año y febrero del siguiente vivió Zaragoza. ${ }^{1}$

1 Sobre el asunto, sirven de referencia MARTíNEZ RUIZ (2008a; 2008b). 
Los planteamientos tácticos y estratégicos de aquel momento primaban unos usos de la guerra que daban protagonismo a las batallas en campo abierto, con la infantería como reina de las mismas, apoyada por la artillería. ${ }^{2}$ En ese contexto, el anterior predominio de las guerras de sitio había quedado superado. Si los asedios habían sido una constante en las guerras hasta el siglo XVIII, a principios del XIX ya tenían menor relevancia ante los avances técnicos logrados en las armas de fuego. Sin embargo, durante la Guerra de la Independencia española hubo un importante número de sitios tanto de plazas fuertes como de puestos fortificados (ESCRIBANO, 2009: 196). ${ }^{3}$ En parte, porque todos ellos continuaban siendo importantes para controlar los territorios y localidades adyacentes (MEDINA, 2009: 285). ${ }^{4}$

Ciertamente, no parece que la capital aragonesa fuera un lugar idóneo para resistir el asedio de la Grande Armée. Como otras grandes ciudades de vasto perímetro, su fortificación había quedado completamente obsoleta para los usos bélicos de aquel momento. En palabras del citado Francisco Escribano, más que fortificada, la ciudad estaba rodeada "por tapias de conventos, lienzos de murallas (romanas, árabes o de la Reconquista) y unas puertas cuya función no era defensiva sino fiscal, pues con ellas sólo se pretendía cobrar los aranceles a quienes quisieran comerciar en su interior" (ESCRIBANO, 2009: 200). ${ }^{5}$

Aun así, Zaragoza ofreció una feroz resistencia ante los franceses, y su lucha contra un enemigo muy superior sirvió de acicate a los combatientes de otros puntos de la Península a la hora de plantar cara al avance de las tropas napoleónicas. Una de las características de aquella lucha fue

2 Véanse BLACK (2000: 157 y ss.); y HOWARD (2009: 75 y ss.).

3 Para profundizar en aspectos técnicos de los asedios en aquellos años, también resulta muy interesante el estudio de HERRERO (2001).

4 Sobre los asedios a urbes durante el conflicto que nos ocupa, Andrés Cassinello señalaba: "Nuestra Guerra de la Independencia fue el último recurso generalizado a este tipo de guerra, que tuvo su final en Sebastopol o Stalingrado. En Cataluña se produjeron los Sitios de Girona, Lleida, Tarragona, Rosas, Tortosa, y un puñado más de poblaciones y fortalezas; en Valencia, la misma capital, Peñíscola y Murviedro; en León, Astorga y Ciudad Rodrígo; en Extremadura, Badajoz y Olivenza; en Andalucía, Cádiz y Tarifa, y en Aragón, por dos veces, Zaragoza" (CASSINELLO, 2007: 85).

5 En similar sentido, interesa la referencia en SANTACARA (2005: 68). Miguel Alonso Baquer resumía las operaciones españolas durante la Guerra de la Independencia distinguiendo tres tipos: las operaciones propias de un Ejército regular, las propias del viejo sistema defensivo de las milicias provinciales (centradas en la protección de las ciudades), y las operaciones del movimiento guerrillero que fue surgiendo tras la invasión napoleónica (ALONSO, 2009: 33). 
la implicación del conjunto de la población en el empeño por detener al enemigo e imposibilitar su avance por la ciudad. ${ }^{6} \mathrm{Y}$ dentro de ella, la participación femenina adquirió un lugar destacado.

\section{LAS COMBATIENTES DE LOS Sitios de ZaRAgoza}

Es lugar común afirmar que las mujeres, desde tiempos inmemoriales, han tomado partido en las guerras, sobre todo en labores de aprovisionamiento y de atención a las tropas (NASH y TAVERA, 2003; FERNÁNDEZ, 2010). Sin embargo, dicha actuación tiene como principal característica el anonimato de sus protagonistas. Frente a ello, los Sitios de Zaragoza van irremediablemente asociados a nombres como los de Agustina Zaragoza, Manuela Sancho, María Agustín, Casta Álvarez, la condesa de Bureta o la madre Rafols, entre otras.?

Una presencia, la de estas mujeres, que ha pervivido en la memoria colectiva o en el callejero de la ciudad, y que ya desde los primeros momentos fue documentada por los testigos de la misma. Entre estos testimonios de la resistencia de la urbe aragonesa, los padecimientos de su población y la implicación colectiva en la lucha, incluida la femenina, destacaron los pictóricos, en especial los grabados de Francisco de Goya en su serie Desastres de la Guerra, o de Juan Gálvez y Fernando Brambila en Las Ruinas de Zaragoza. ${ }^{8}$ De igual modo, durante la Guerra de la Independencia y en los años posteriores, las autoridades militares y civiles que habían asumido algún tipo de mando castrense en los Sitios de Zaragoza emitieron certificaciones e

6 Un levantamiento de los habitantes de la ciudad que recuerda el concepto de nación en armas que precisamente la Revolución Francesa acabó exportando al resto del continente. Entre la abundante bibliografía relativa a dicho concepto o su aplicación a la Guerra de la Independencia española, pueden ser de utilidad BEST (1990: 156); HOCQUELLET (2008: 134 y ss.); RÚJULA (2009); y KEEGAN (2014: 465-470). Una interesante visión sobre la extensión del combate al conjunto de la sociedad y su trágica consecuencia del mayor alcance de la violencia al conjunto de la misma, en RÚJULA (2012: 35). Sobre la presencia popular en la guerra de sitio, Richard Hocquellet y Stéphane Michonneau apuntaban: "La raison de cet enthousiasme vient de ce que la guerre de siège met en valeur la composante civique du conflit. Le siège s'installe dans la durée et repose sur la cohésion et l'organisation de la résistance du pueblo" (HOCQUELLET Y MICHONNEAU, 2008: 103).

7 Sobre ellas, sirven de referencia, LAFOZ (1996: 226); AYMES (2008: 356-364); ESPIGADO (2009: 715 y ss.); FERNÁNDEZ (2009b: 44-66); y MARÍN (2009).

8 La imagen visual de la Guerra de la Independencia ha sido analizada por REYERO (2008). También merecen atención los escritos producidos en aquellos años por el cronista de la ciudad, Faustino Casamayor y Ceballos. 
informaciones sobre el activo papel de estas heroínas. Numerosos escritos reflejaron las meritorias acciones protagonizadas por la más afamada de aquellas protagonistas femeninas de la resistencia aragonesa frente a los franceses: Agustina Zaragoza Doménech. Por ejemplo, el capitán del Regimiento de Dragones del Rey, don José López de Ansó, señalaba de ella:

"se me presentó en el mes de Junio de 1808 luego que los enemigos sitiaron la Ciudad [...] se ofrecio voluntariamente á hacer el servicio que pudiese en la Puerta del Portillo, lo que verificó con un valor extraordinario, particularmente en el $1^{\circ}$ de Julio del mismo año en que atacando los enemigos con el mayor impetu dicho punto para penetrar en la Ciudad; y habiendo mucha falta de Artilleros por haber perecido algunos de los pocos que habia con la multitud de bombas y granadas que dirigian sobre la bateria, viendo la citada Zaragoza se aproximaban y no habia quien diese fuego á un cañon que estaba cargado, tomó la mecha y disparó, causandoles una gran perdida, y obligandoles á que se retirasen". 9

También es sobradamente conocida la información sobre Manuela Sancho dada por don Mariano de Renovales, en calidad de comandante del fuerte de San José, al general Palafox, en la que recogía como esta:

"tanto en el ataque del dia último de año pasado, como en el de ayer

9 El referido Oficial continuó su relato con la participación de la Heroína en el Segundo Sitio de la ciudad, donde prestó sus servicios nuevamente en la puerta del Portillo, para proseguir luego sus desvelos en la Misericordia y en el convento de Trinitarios. Archivo Municipal de Zaragoza (en adelante AMZ), fondo Palafox, sig. 3-5/3, año 1814. De esta protagonista se conservan otras certificaciones en similar sentido emitidas por autoridades militares de diferentes lugares o enfrentamientos contra los franceses. Sirvan de ejemplo las rubricadas por el conde de Alacha, de la presencia de Agustina Zaragoza en la defensa de la plaza de Tortosa de 1810 (AMZ, fondo Palafox, sig. 3-5/4, año 1814), o por el mariscal de campo Pablo Morillo, de sus buenos servicios en la batalla de Vitoria (AMZ, fondo Palafox, sig. 3-5/5, año 1814). Mención aparte merece la celebérrima y muy posterior certificación de don José Rebolledo de Palafox y Melci, Capitán General del Ejército y Reino de Aragón, en la que acreditaba el valor y patriotismo exhibidos por Agustina durante los Sitios de la capital, distinguiendo especialmente su citada actuación de primero de julio en la batería del Portillo, así como la concesión por el propio Palafox de la graduación y el sueldo que gozaba el sargento de Artillería a quien la heroína había tan dignamente reemplazado en su afamada acción. $A M Z$, fondo Palafox, sig. 3-5/8, año 1833. 
sirvió la artillerìa y mortero como pudiera haberlo hecho el mejor artillero, conduciendo cartuchos para los unos, y piedras para el otro, sin haberle notado la menor mutacion, á pesar de haber caído algunos a su lado: dió fuego á algunos cañones, y lo hizo de fusil en la trinchera como uno de tantos". ${ }^{10}$

Otras protagonistas no son tan conocidas como las anteriores, pero no por ello ganaron menos méritos. Además, sus acciones también eran certificadas por diferentes testigos. Fue el caso de doña María Ramírez de Arellano, quien junto a su hijo Juan Puch, hizo gala de patriotismo y sacrificio en los dos Sitios de la ciudad. Por ello, el mariscal de campo don Francisco Marco del Pont, en calidad de comandante que había sido de la batería del Portillo, daba cuenta que:

"doña Maria Ramirez de Puch pasó en el primer Sitio á llevar biveres y municiones á la expresada bateria en medio de los mayores riesgos, manifestando siempre mucho patriotismo y celo por la justa causa" ${ }^{\prime 1}$

Sobre Josefa Buil, Luis Lapuente, el alcalde de barrio de la parroquia de la Magdalena que había comandado una porción de paisanos contra los franceses, afirmaba que:

"Josefa Buil fue una de las mugeres que mas se distinguieron en el segundo asedio de esta ciudad en los puntos del arco de Valencia y plaza de la Magdalena, y que dicha Buil hacia las fatigas correspondientes como uno de los mejores soldados tanto de dia como de noche". ${ }^{12}$

10 Recogido en Gaceta de Zaragoza, 7 de enero de 1809. Como esta, Manuela Sancho recibió otras certificaciones de su actuación y su valor durante los Sitios de la ciudad por parte del general Palafox, del brigadier don Alberto Sagastibelza o del duque de Villahermosa, que era coronel de Dragones. AMZ, fondo Palafox, sig. 3-10/2, año1818, ff. 1r-2r, 3r y 4r y v, respectivamente.

11 El papel de doña María también fue certificado por don Fernando Gómez de Butrón, mariscal de campo de los Reales Ejércitos. Ambas citas en AMZ, fondo Palafox, sig. 21-4/2-3, años 1814-1817, f. 1r y 3r, respectivamente. También fue recogida su actividad en $A M Z$, fondo Palafox, sig. 13-6/51, año 1817, f. 10r y v. y sig. 13-2/82, año 1817, f. 1ry v. 
Como puede observarse en las diferentes citas, los jefes militares que habían sido testigos de las acciones de las vecinas de Zaragoza durante los Sitios de la ciudad recogían una variada actividad de las mismas. Como es lógico, se reflejó su papel en las labores de atención a las necesidades de la tropa que directamente combatía. Teresa García, una vecina de la parroquia de Santa Engracia de la ciudad, había asistido pública y notoriamente "en el tiempo de los ataques de esta ciudad, con refresco á las tropas de las Baterias, y Puertas." ${ }^{13} \mathrm{Y}$ de la condesa de Bureta, en particular, y otras muchas zaragozanas en general se escribía en uno de los muchos relatos épicos de los Sitios zaragozanos:

"Las mugeres se conduxeron como heroinas, simpatizando admirablemente con el valor y gallardía de los hombres. La Condesa de Bureta, Dama distinguida del pais, viuda del Conde de este título, y esposa en el dia del Regente de la Real Audiencia de Aragon, formó un cuerpo con las de su sexô destinadas únicamente á socorrer á los heridos, y á llevar vino y provisiones á los soldados. Muchas personas fidedignas declaran, haber visto á menudo esta muger delicada y bella llenando con mucha serenidad los deberes que se habia impuesto en medio del fuego, de las balas, bombas y granadas del enemigo". ${ }^{14}$

En otras ocasiones, la participación de estas heroínas fue ambivalente, dedicándose principalmente a labores de abastecimiento, más propias de su sexo en la escala de valores de la época, pero no dudando en empuñar las armas ante la necesidad de ello. De Manuela Sancho se refleja como:

$12 Y$ en similares términos se expresaba uno de los mayordomos del Hospital de Niños Huérfanos de la ciudad, presente en la contienda. AMZ, fondo Palafox, sig. 3-7/5, año 1818, f. 1ry lv, respectivamente.

13 AMZ, fondo Palafox, sig. 22-8/77, año 1808. Sobre ellas, véase RUDORFF (1977: 133).

14 AMZ, fondo Palafox, sig. 1-6/3, año 1809, f. 12r. Muy interesantes resultan, en este sentido, los informes de la condesa de Bureta describiendo su propia actuación durante la contienda. Véase MARÍN (1999: 98-100 y 107-109). De este tipo de participación femenina en la guerra, Elena Fernández señalaba: "aunque históricamente las mujeres siempre han llevado a cabo tareas de asistencia a los ejércitos, no será hasta el contexto de la Guerra de la Independencia cuando desde las instituciones militares y de gobierno se de relevancia pública a unas funciones que resultaban básicas para asegurar el triunfo de las tropas sobre el enemigo francés" (FERNÁNDEZ, 2011 b: 73). 
"Desde antes de romper el dia hasta que anochece no cesa de conducir, pan, vino, aguardiente, y otras frioleras; en los mayores apuros del ataque, se ha desentendido de este servicio, y se ha dedicado al de la artillería con la mayor serenidad, conduciendo municiones, y piedras à canastas para el mortero, dando fuego por sí à los cañones, y haciendolo por los parapetos con el fusil, sin que se le haya conocido la menor mutacion à pesar de haber caìdo algunos à su lado". ${ }^{15}$

E incluso, algunas de las certificaciones hacen referencia únicamente a las acciones militares que protagonizaron algunas de estas mujeres. En la declaración de la conducta observada en tres vecinas de la ciudad durante la contienda se recogía:

"Josefa Buil natural de Barbastro se halló en dicha ciudad durante el segundo asedio y la vi hacer fuego en una de las baterias de la plaza de la Magdalena en compañia de Benita Portoles natural de Alcañiz, y Teresa Liesa natural de Huesca, especialmente en la esquina de la calle de Palomar en cuya casa habitaba la expresada Benita Portoles". ${ }^{16}$

Toda esta documentación relativa a las mujeres que destacaron por su heroísmo durante los Sitios de la ciudad tuvo un único origen, pero muy diferentes finalidades. Respecto al origen de dicha documentación cabe señalar que fue la propia actuación "masiva" femenina la que provocó que aparecieran tantas listas de participantes en la resistencia de la ciudad ante los franceses en las que se incluían féminas, así como numerosas misivas en las que se hacía referencia a ellas, y un sinfín de certificados y notas avalando su conducta en la contienda. Frente al tradicional veto existente durante aquellos siglos a la participación femenina directa en los conflictos bélicos, los Sitios de Zaragoza constituyeron una interesante excepción. En

15 Gaceta de Zaragoza, 7 de enero de 1809, p. 14. También recogido en AMZ, fondo Palafox, sig. 47-13, año 1818.

16 AMZ, fondo Palafox, sig. 3-7/5, año 1818, f. 1v. Aunque el empuñamiento de las armas por manos femeninas no dejaba de ser un quebranto de los roles femeninos imperantes, como señalaba Juan José Sánchez "cuando la gente emprende un alzamiento, la ruptura del orden existente puede extenderse también a las barreras de género, que al fin y al cabo son injustas, discriminatorias y con frecuencia bastante arbitrarias" (SANCHEZ, 2008: 699). 
primer lugar, la neta superioridad del enemigo frente a las tropas atrincheradas en la ciudad facilitó la respuesta popular en ayuda y auxilio de los suyos para resistir el embate francés. Y dentro de esa respuesta popular, la dada por las propias vecinas tuvo su protagonismo.

Esta movilización provocó la cercanía física de las mujeres a los lugares de combate. ${ }^{17}$ Pese a que en un principio su papel pudo centrarse en labores de abastecimiento y sostenimiento a las tropas masculinas (las implicadas directamente en las operaciones), las mujeres cobraron relativa proximidad y familiaridad con la primera línea de frente y con las armas que finalmente acabaron enarbolando. De este modo, en gran medida, estas zaragozanas atrapadas dentro de su ciudad no pudieron, y quizá no quisieron, quedar al margen de la guerra que la asolaba. ${ }^{18}$

La primera finalidad de la citada documentación hay que buscarla en el intento de las interesadas de obtener alguna distinción o una pensión por los sufrimientos pasados y el patriotismo exhibido, o la concesión de las mismas por la autoridad pertinente.

Don José Palafox, por ejemplo, distinguió a Agustina Zaragoza con el escudo de defensora de la patria por su valor y los servicios prestados en la defensa de la ciudad. Y también se le concedió el permiso para usar la cruz de distinción de la participación en el Primer Sitio de Zaragoza. ${ }^{19}$ Además, la Junta Suprema Central de Gobierno de España e Indias, en nombre de Fernando VII, otorgó a Agustina Zaragoza el grado y sueldo de subteniente de Infantería. ${ }^{20}$

17 Acerca del papel femenino en el campo de batalla, Nira Yuval-Davis afirmaba: "Clear sexual division of labour in war, however, usually disappears when there is no clear differentiation between the battle front and the home front or rear" (YUVAL-DAVIS, 1997: 95).

18 Similar había sido la situación vivida pocos años antes por las mujeres que se vieron atrapadas en los acontecimientos de la Revolución Francesa, que en numerosos casos tomaron parte de los acontecimientos que se desarrollaban en su entorno (LEVY y APPLEWHITE, 1992; y BECKSTRAND, 2009). También interesante la reflexión recogida sobre estas mujeres en LYNN (2008: 208-214).

$19 \mathrm{AMZ}$, fondo Palafox, sig. 3-5/1, año 1808 y sig. 3-5/7, año 1817, respectivamente.

$20 \mathrm{AMZ}$, fondo Palafox, sig. 3-5/2, año 1809. Como se vio con anterioridad, el general Palafox certificó posteriormente haber concedido a Agustina, haciendo uso de las amplias facultades de las que gozó durante la contienda, y como estímulo al resto de defensores de la ciudad, ya durante el mismo asedio el grado y sueldo del sargento de Artillería al que tan dignamente había reemplazado. Véase nota 9. 
De igual modo, acabada la contienda, se recogieron informes y memoriales sobre la actuación de diferentes mujeres que participaron en la defensa de la ciudad y las solicitudes para premiarlas con las anteriormente citadas condecoraciones. Entre ellas se encontraban María Lostal, Eugenia Cubeño, María Gali, Benita Portolés, Manuela Barrena o Ana Sánchez. ${ }^{21}$

El propio Capitán General premió a Manuela Sancho con el "distintivo de la cinta encarnada" y media peseta diaria de pensión. ${ }^{22}$ Y lo mismo hizo con Josefa Buil, a la que otorgó una pensión de cinco reales de vellón diarios "en premio de su celo, y continuo trabajo en las Baterias, haciendo el mismo servicio que un soldado." 23

También reclamaba una pensión de viudedad María Montalbán, una zaragozana que había tenido una heroica actuación durante los dos Sitios, habiendo perdido en el segundo a su marido, señalando entre sus méritos:

"que la recurrente se ocupó en los dos [Sitios], en conducir cartuchos á la Artilleria, y refrescos para los que ocupaban los puestos abanzados, depreciando la muerte que en todas direcciones la amenazaban, y que despues de rendida dicha Plaza se trasladó á la de Tortosa ejercitandose en iguales servicios". ${ }^{24}$

Similar situación en la que debía encontrarse María Paracuello, una viuda vecina de Zaragoza que también había perdido a su marido durante el segundo asedio a la ciudad. El general Palafox solicitó para ella la concesión de alguna limosna por los servicios que había prestado junto a su marido durante los Sitios. ${ }^{25}$

No menos importante que el propio interés de las protagonistas femeninas de las que venimos tratando fue el de las autoridades militares y civiles

21 AMZ, fondo Palafox, sig. 12/145-247, año 1814, sig. 10-1/29, año 1808, sig. 13-1/1-36, año 1815 y sig. 13-5/1-22, año 1815. Peticiones de premio a las que ni siquiera la ciudad fue ajena. Acabada la contienda, el consistorio zaragozano solicitaba al general Palafox su informe favorable a la petición de la capital aragonesa al rey para recibir los títulos de "muy noble, fidelísima y heroica". AMZ, fondo Palafox, sig. 13-2/1-2 y sig. 44-5/15, año 1817.

22 Gaceta de Zaragoza, 7 de enero de 1809, pp. 13-15.

$23 \mathrm{AMZ}$, fondo Palafox, sig. 3-7/3 y 4, año 1818 y sig. 3-7/8, año 1821.

$24 \mathrm{AMZ}$, fondo Palafox, sig. 3-8/72, año 1828, ff. $1 \mathrm{r}-2 \mathrm{r}$.

25 AMZ, fondo Palafox, sig. 46-17/45-46, año 1818. 
que quisieron extender el ejemplo de la población de Zaragoza y su tenaz resistencia a otras localidades y territorios peninsulares. ${ }^{26}$ La capital aragonesa se convirtió en paradigma de lucha, una pugna que había sido protagonizada por toda la sociedad, incluido el sector femenino. ${ }^{27}$ Así se certificó y publicó, para de ese modo provocar la movilización del esfuerzo popular (DE DIEGO, 2005: 15; CASTELLS, ESPIGADO y ROMEO, 2009: 16; FERNÁNDEZ, 201 1a: 45-46).

Fruto de aquel interés de las autoridades fue la construcción de auténticos mitos en torno a la figura de algunas de estas mujeres. La más clara muestra de ello fue, sin duda, Agustina de Aragón, cuya persona y actuación quedaron ensalzadas desde un primer momento por los propios protagonistas de los Sitios que compartieron lucha con ella. ${ }^{28}$ Posteriormente, Agustina ha sido citada y representada en todo tipo de obras, tanto literarias como historiográficas, pictóricas, escultóricas y cinematográficas, y por muy diferentes motivos, especialmente coincidiendo con la celebración de actos conmemorativos. ${ }^{29}$

De modo similar al caso de Agustina, otras mujeres que participaron en los Sitios de Zaragoza fueron, con nombres propios, ensalzadas como heroínas y su actuación sirvió como aglutinante de otras muchas acciones femeninas anónimas llevadas a cabo durante los enfrentamientos contra

26 Las diferentes tipologías de los diversos discursos patrióticos elaborados durante la Guerra de la Independencia española han sido analizadas por HOCQUELLET (2008: 11-15).

27 Como han señalado José Gregorio Cayuela y José Ángel Gallego, Zaragoza, además del mito popular y político que representó, destacó por suponer con su resistencia la continuación más destacada del 2 de mayo en Madrid, por primar el papel de la resistencia popular por encima del propio Ejército regular encabezado por el general Palafox y por convertirse en un importante referente no solo para el resto de poblaciones resistentes en la Península, sino para los propios franceses (CAYUELA y GALLEGO, 2008: 109-1 10). También resulta interesante, en este sentido, las vivencias expuestas por el oficial británico Charles Doyle, sobre la resistencia zaragozana que presenció en primera persona. Recogido en LASPRA (2010: 257).

28 En algunos casos, los testimonios procedieron incluso del bando francés, BELMAS (2003: 30); y LEJEUNE (2009: 14).

29 Entre los múltiples trabajos de análisis de estas obras, pueden ser de utilidad ÁLVAREZ BARRIENTOS (2009); SALAS (2007); ROMERO (2009); MARTíNEZ ÁLVAREZ (2010); y FREIRE (2014). El trato dado a las heroínas zaragozanas durante la conmemoración del centenario de la Guerra de la Independencia fue estudiado por MORENO LUZÓN (2004: 58 y ss.). María Pilar Queralt, por su parte, trató de separar, en su biografía de Agustina de Aragón, el papel histórico de la heroína y su personaje mitificado (QUERALT, 2008). 
los franceses en aquellos años (CAYUELA y GALLEGO, 2008: 115; SERRANO, 2010: 164-165). ${ }^{30}$ La actuación de todas estas mujeres valerosas fue un arma ampliamente utilizada por la propaganda patriótica y símbolo de la lucha popular por la libertad nacional (FERNÁNDEZ, 2009a: 794).

Obviamente, un análisis objetivo de este proceso mitificador también muestra ciertas fisuras en el mismo. La gesta de Agustina de Aragón, como ha puesto de manifiesto la historiografía, coincide con bastante fidelidad con el relato mítico de otras heroínas, como el de la norteamericana Molly Pitcher durante la Guerra de Independencia de las colonias británicas (CASTELLS, ESPIGADO y ROMEO, 2009: 29; UCELAY DA CAL, 2009: 213). ${ }^{31}$ Y tal como ha sido señalado por algún autor, algunas de las heroínas zaragozanas recibieron honores y pensiones tras realizar acciones corrientes entre los soldados, como reemplazar a un compañero caído, muestra de la excepcionalidad de ser protagonizados por mujeres y del interesado discurso movilizador de las autoridades (TONE, 1999: 263). María Pilar Queralt mostraba la mezcla de cotidianeidad y casualidad que se daba en la presencia de la propia Agustina en la capital aragonesa durante los Sitios de la ciudad. Al preguntarse qué hacía una joven catalana en Zaragoza, concluía: "Simplemente, seguir a su esposo. En la época era habitual que los soldados se trasladaran con sus esposas que, en caso de necesidad, colaboraban manteniendo la intendencia del regimiento". (QUERALT, 2005: 28-29). ${ }^{32}$

De igual manera, como puede observarse en lo tardío de algunas de las certificaciones citadas, el discurso mítico de la actuación de estas zaragozanas persistió bien entrado el siglo XIX, sirviendo de argumento al nacimiento del estado-nación liberal español (ÁLVAREZ JUNCO, 1994; 1997;

30 Mientras que en los primeros momentos de la Guerra de la Independencia la participación femenina tuvo algunos nombres propios, a lo largo del transcurso de la contienda, el discurso se fue alterando y se primó al grupo, dando prioridad a una iconografía de la feminidad menos amenazante (ESPIGADO, 2009: 722). Sobre la existencia de dos modelos de mujer, en buena medida antagónicos, en los discursos patrióticos de aquellos años, el de la matrona y el de la heroína, véase FERNÁNDEZ (2009a). También de interés, JIMÉNEZ (2005: 363-364); y ROMEO (2006: 63).

31 El papel femenino en la Guerra de la Independencia americana fue analizado por BOHRER (2003: 155 y ss.) y BERKIN (2005: 50-56).

32 En este caso, a su marido Juan Roca, implicado en varias de las acciones del Ejército en tierras catalanas y aragonesas. Sobre la llegada de Agustina a la Zaragoza, interesa QUERALT (2008: 71-72). 
2016: 155 y ss.; GARCÍA CÁRCEL, 2007; ÁlVAREZ JUNCO y DE LA FUENTE, 2017: 279-280). ${ }^{33}$ Roberto López Vela señalaba que: "En la mitología del siglo XIX los acontecimientos de la guerra contra los franceses ocupan un lugar central y en torno a su explicación se construye toda una imagen de la nación" (LÓPEZ VELA, 2004: 289). Una mitología nacionalista que los principales partidos decimonónicos supieron explotar en su beneficio. José Álvarez Junco observaba:

"La canonización del conflicto de 1808-1814 como Guerra de la Independencia, acabó dando lugar a un motín nacional casi perfecto, porque, tras ser una creación liberal, acabó sobrevolando por encima de los partidismos políticos. Los liberales siguieron basando en aquella actuación del pueblo su pretensión de construir un edificio político a partir del dogma de la soberanía nacional; pero los conservadores no dudaban en presentar la heroica pugna de 1808 como prueba de la fidelidad del pueblo español a la tradición heredada" (ÁLVAREZ JUNCO, 2001: 144). ${ }^{34}$

Además, el encumbramiento glorioso de las heroínas (como el que se hizo de destacados guerrilleros en particular y del pueblo en general) sirvió para desviar la atención sobre las deficiencias y carencias de las que adolecía el Ejército regular español, y su clara inferioridad frente al enemigo galo. ${ }^{35}$

Y, por último, no conviene olvidar el propio interés de algunas de las autoridades militares que generaron un discurso propagandístico que elevaba

33 La memoria de algunas heroínas se reavivó décadas después, en el momento de su deceso, como fue el caso de Manuela Sancho o el de la propia Agustina. AMZ, fondo Palafox, sig. 3-10/3, año 1863. De la primera se recordaba, en un artículo publicado con motivo de su óbito, "fué un ejemplo vivo y constante de patriotismo y de valor" durante los Sitios de la ciudad y se destacaba como en los momentos más dramáticos de la contienda "nuestra heroina empuña un fusil y olvidándose de su secso y recordando solo que es española, se bate vigorosamente por espacio de algunas horas y logra la dicha de que su nombre se cite como modelo en los partes del jefe del puesto y en los documentos oficiales de la época." Diario de Zaragoza, 2 de mayo de 1863.

34 También de interés FUENTES (2013: 183).

35 Sobre la situación del Ejército español que hubo de encarar la Guerra de la Independencia existe un interesante estudio en CASSINELLO (2008a: 231-235). 
la actuación de las zaragozanas y los zaragozanos al nivel de gesta épi$\mathrm{ca}$, para de ese modo ensalzar la suya propia o incluso hacer olvidar los posibles errores cometidos en el ejercicio del mando durante los célebres asedios a la ciudad.

El caso paradigmático, en este sentido, fue el del general Palafox, cuya figura y papel durante la Guerra de la Independencia han recibido una importante revisión historiográfica. ${ }^{36}$ Palafox ha sido definido como "un aristócrata militar dotado de mayor talento y vocación políticos que castrenses", empeñado, durante los años posteriores a la contienda, en un infructuoso intento de escribir unas memorias para justificar su actuación y engrandecer su carrera militar (que no fue brillante) con su protagonismo en los Sitios de Zaragoza (LAFOZ, 1992: 40; DURÁN, 2002: 73-74; CUENCA, 2006: 135).

El relato del General recoge su interés en encumbrar la resistencia al asedio de la capital aragonesa junto a los más relevantes episodios bélicos de este tipo acaecidos a lo largo de nuestra historia, remarcando su propio protagonismo en el mismo:

"La primera plaza, el primer pueblo, que sostuvo por dos veces el más heroico y empeñado sitio que cuentan nuestros anales militares, incluso Sagunto y Numancia, fue Zaragoza, siendo yo el encargado de dirigir su defensa".

Igualmente, Palafox trató de justificar su quizá excesivo entusiasmo a la hora de loar la resistencia zaragozana al ataque galo:

"Los dos Sitios de Zaragoza ocuparán siempre interesantes trozos de nuestra historia; nuestros hijos, al leerlos, se creerán mágicamente transportados a los tiempos heroicos, y es tolerable si nos exaltamos algún tanto al recordar memorias tan preciosas. Lícita le es al hombre la ambición de gloria, séale pues permitido igualmente el recordar a sus semejantes aquellos hechos en que tuvo tanta parte, señalándose en tan grandiosas hazañas" (PALAFOX, 1994: 34 y 36, respectivamente)..$^{37}$

36 Al respecto, son de interés ESDAILE (2004: 201); DURÁN (2008); y GARCÍA CÁRCEL (2010: 30).

37 Manuel Moreno Alonso destacaba la ausencia de cualquier autocrítica del General a su propia actuación al elaborar su relato autobiográfico (MORENO ALONSO, 2008: 23). 
Algún autor, incluso, ha destacado lo erróneo de su escasa actuación durante la Guerra de la Independencia, desde sus fracasos en los enfrentamientos regulares abiertos contra los franceses en el frente del Ebro, hasta la absurda decisión de atrincherarse en una ciudad como Zaragoza y mantener una defensa de la misma que supuso un enorme desgaste humano y que tuvo una nula utilidad militar (CASSINELLO, 2006: 71 y 76; 2008b: $131) .{ }^{38}$

Y haciendo referencia específicamente a la participación femenina en la contienda, la postura del general Palafox no debió ser muy favorable en principio, aunque también es cierto que no tardó en mudar su opinión. Gloria Espigado advertía:

"En verdad, las primeras reacciones ante la iniciativa femenina fueron, como cabría esperar, de rechazo. Las autoridades recriminaron, en primera instancia, la salida de tono de las mujeres y las conminaron a permanecer en su lugar dentro del recinto doméstico. Palafox, en los inicios del primer embate a la ciudad, también ordena que niños, mujeres y ancianos permanezcan en sus casas, pero he aquí que es el primero en cambiar de opinión y percatarse del potencial que encierra no sólo la participación femenina, sino la noticia de la participación femenina, para a partir de ahí aconsejar y animar su implicación" ${ }^{39}$

En cualquier caso, Palafox fue un personaje complejo cuyo origen nobiliar, su educación ilustrada y su defensa del rey despertaron desconfianzas entre los sectores populares y entre las élites, tanto liberales como conservadoras. Y aunque ocupó la Capitanía General de Aragón durante los Sitios y la recuperó tras la contienda, en 1815 se vio obligado a retirarse de la misma y fue viendo frustradas muchas de sus expectativas. Como indicó Pedro Rúiula: "Poco a poco Palafox tuvo que acostumbrarse a ocupar siempre aquella posición que no deseaba" (RÚJULA, 1994: 11).

No hizo, por otra parte, el antiguo Capitán General otra cosa que tratar de aprovecharse de los acontecimientos desarrollados durante los Sitios de Zaragoza y del ascendiente del que gozaban las mujeres que habían

38 Igualmente interesante la crítica realizada por PEIRÓ (2017). También existen estudios que defienden la labor militar de Palafox, como por ejemplo, PERLA (2009).

39 ESPIGADO (2009: 721). 
combatido en ellos. Poco difirió su actitud con la que tuvieron las diferentes facciones políticas que se disputaron el poder en la España del XIX, así como diversas instituciones, entre las que destacaron la Iglesia y la Corona.

\section{CONCLUSIONES}

Por lo hasta aquí visto, puede concluirse que la documentación conservada de los Sitios de la ciudad de Zaragoza en la Guerra de la Independencia española evidencia la participación de sus vecinas durante ambos asedios. Dicha participación se centró en labores logísticas y de apoyo a las tropas masculinas que hacían frente al enemigo francés. Sin embargo, la proximidad femenina a la primera línea de combate también les brindó la ocasión de sobresalir en las destacadas actuaciones militares que se desarrollaron durante los Sitios. Su participación y el sufrimiento que les acarrearon algunas de sus hazañas bélicas les permitieron salir del anonimato que caracterizaba la actuación femenina en las contiendas de aquellos siglos.

Además, tales acciones fueron reconocidas por las autoridades militares, quienes expidieron numerosos documentos certificando las hazañas realizadas por aquellas destacadas mujeres. Un buen número de estos documentos se debieron a un interés personal de las propias afectadas, que de esa manera justificaban la concesión de distinciones y pensiones que consideraban merecer por sus heroicas conductas durante la guerra. Buscaron con ello paliar la pobre situación en la que muchas de ellas quedaron tras la retirada francesa, agravada en muchos casos por la pérdida de familiares y bienes durante los Sitios.

En otras ocasiones, el interés provino de las propias autoridades militares y civiles que trataron de elaborar un discurso patriótico que en un primer momento sirviera de acicate movilizador de la mayor parte de la población contra la invasión napoleónica, para posteriormente utilizarlo en la propia construcción nacional del estado liberal a lo largo de todo el siglo XIX.

Frente a un enemigo netamente superior al Ejército español existente en la época, las autoridades hispanas trataron de movilizar a toda la población contra los franceses. Y en ese contexto, Zaragoza y sus habitantes, entre ellos y con nombre propio un buen puñado de mujeres, supusieron un ejemplo mitificado que corrió por la Península y se convirtió en símbolo de la resistencia de todo un pueblo contra la invasión.

Una labor propagandística de la resistencia de la capital aragonesa que tuvo como uno de sus principales promotores a quien encabezaba su Ejército, el general Palafox. Un militar cortesano al mando de una tropa muy inferior a la que tenía que hacer frente, con la necesidad de resistir el sitio de una ciudad mal fortificada, y en la que el impulso y sacrificio de la 
población explican buena parte del coste que la toma de la plaza supuso para los franceses. En las décadas siguientes, Palafox trató de manejar con astucia las circunstancias que caracterizaron los Sitios para justificar sus decisiones y añadir lustre a su propia actuación, encumbrando al tiempo a algunas de sus protagonistas a la categoría de mito.

Y ese mismo mito patriótico que había servido para movilizar a la población contra el invasor foráneo se utilizó a lo largo de todo el siglo decimonónico y los albores del XX para un discurso nacional que sirviera de justificación de la creación de un estado liberal.

\section{Bibliografía}

ALONSO BAQUER, Miguel (2009), "La conducción de las operaciones en la Guerra de la Independencia", en MARTíNEZ RODA, Federico (ed.), Actas del Congreso sobre la Guerra de la Independencia y los cambios institucionales, Diputación de Valencia, Valencia, pp. 29-49.

ÁLVAREZ BARRIENTOS, Joaquín (2009), "1808-1814. Escritores en guerra. El concurso literario por los Sitios de Zaragoza", en DE DIEGO, Emilio (dir.) y MARTÍNEZ SANZ, José Luis (coord.), El comienzo de la Guerra de la Independencia. Congreso Internacional del Bicentenario, Editorial Actas, Madrid, pp. 589-626.

ÁLVAREZ JUNCO, José (1994), "La invención de la Guerra de la Independencia", Studia Historica - Historia Contemporánea, vol. XII, pp. 75-99.

ÁlVAREZ JUNCO, José (1997), "El nacionalismo español como mito movilizado. Cuatro guerras", en CRUZ, Rafael y PÉREZ LEDESMA, Manuel (eds.), Cultura y movilización en la España contemporánea, Alianza, Madrid, pp. 35-67.

ÁlVAREZ JUNCO, José (2001), Mater dolorosa. La idea de España en el siglo XIX, Taurus, Madrid.

ÁlVAREZ JUNCO, José (2016), Dioses útiles. Naciones y nacionalismos, Galaxia Gutenberg, Barcelona.

ÁLVAREZ JUNCO, José y DE LA FUENTE, Gregorio (2017), El relato nacional. Historia de la Historia de España, Taurus, Madrid.

AYMES, Jean-René (2008), La Guerra de la Independencia: héroes, villanos y víctimas (1808-1814), Milenio, Lleida.

BECKSTRAND, Lisa (2009), Deviant Women of the French Revolution and the Rise of Feminism, Fairleigh Dickinson University Press, Madison.

BELMAS, Jacques (2003), Zaragoza, 1808 y 1809. Los Sitios vistos por un francés, Estudio, prólogo y notas de Herminio Lafoz, Editorial Comuniter, Zaragoza. 
BERKIN, Carol (2005), Revolutionary Mothers. Women in the Struggle for America's Independence, Knopf Book, Nueva York.

BEST, Geoffrey (1990), Guerra y sociedad en la Europa revolucionaria: 1770-1870, Ministerio de Defensa, Madrid.

BLACK, Jeremy (2000), War and the World. Military Power and the Fate of Continents, 1450-2000, Yale University Press, New Haven/Londres.

BOHRER, Melissa L. (2003), Glory, Passion and Principle. The Story of Eight Remarkable Women at the Core of the American Revolutions, Atria Books, Nueva York.

CASSINELLO, Andrés (2006), "El ejército español en la Guerra de la Independencia: un análisis militar", El Basilisco. Revista de Filosofía, Ciencias Humanas, Teoría de la Ciencia y de la Cultura, n 38, 2ª́poca, pp. 65-76. CASSINELLO, Andrés (2007), "Evolución de las campañas militares", en MOLINER PRADA, Antonio (ed.), La Guerra de la Independencia en España (1808-1814), Nabla Ediciones, Barcelona, pp. 73-122.

CASSINELLO, Andrés (2008a), "El ejército español en la Guerra de la Independencia", Revista General de Marina, vol. 255, pp. 23 1-242.

CASSINELLO, Andrés (2008b), "El mando supremo de los ejércitos españoles en la Guerra de la Independencia", en MIRANDA, Francisco (coord.), Guerra, sociedad y política (1808-1814), vol. I, Universidad Pública de Navarra/Gobierno de Navarra, Pamplona, pp. 121-150.

CASTELLS, Irene, ESPIGADO, Gloria y ROMEO, María Cruz (2009), "Heroínas para la patria, madres para la nación: mujeres en pie de guerra", en CASTELLS, Irene, ESPIGADO, Gloria y ROMEO, María Cruz (coords.), Heroínas y patriotas. Mujeres de 1808, Cátedra, Madrid, pp. 15-54.

CAYUELA, José Gregorio y GALLEGO, José Ángel, (2008), La guerra de la independencia: historia bélica, pueblo y nación en España (1808-1814), Ediciones Universidad de Salamanca, Salamanca.

CUENCA TORIBIO, José Manuel (2006), La Guerra de la Independencia: un conflicto decisivo (1808-1814), Encuentro, Madrid.

DE DIEGO, Emilio (2005), "La España de 1808: entre el mito y la realidad", Revista de Historia Militar, n extraordinario «Entre el Dos de Mayo y Napoleón en Chamartín: Los avatares de la guerra peninsular y la intervención británica», pp. 13-33.

DURÁN, Fernando (2002), "Las fuentes autobiográficas españolas para el estudio de la Guerra de la Independencia", en MIRANDA, Francisco (coord.), Fuentes documentales para el estudio de la Guerra de la Independencia, Ediciones Eunate, Pamplona, pp. 47-120. 
DURÁN, Fernando (2008), "Revolución busca caudillo: Palafox y los Sitios de Zaragoza", en ÁLVAREZ BARRIENTOS, Joaquín (ed.), La Guerra de la Independencia en la cultura española, Siglo XXI, Madrid, pp. 23-53.

ESCRIBANO, Francisco (2009), "Los Sitios en la Península Ibérica (18081814): mucho más que mitos", Revista de Historia Militar, $n^{\circ}$ extraordinario "La Guerra de la Independencia. Una visión militar», pp. 195-237.

ESDAILE, Charles J. (2004), La Guerra de la Independencia. Una nueva historia, Crítica, Barcelona.

ESPIGADO, Gloria (2009), "Armas de mujer: El patriotismo de las españolas en la Guerra de la Independencia", en DE DIEGO, Emilio (dir.) y MARTíNEZ SANZ, José Luis (coord.), El comienzo de la Guerra de la Independencia. Congreso Internacional del Bicentenario, Editorial Actas, Madrid, pp. 709-749.

FERNÁNDEZ GARCÍA, Elena (2009a), "Dos modelos de feminidad en las defensoras de la patria: las mujeres en los discursos patrióticos", en DE DIEGO, Emilio (dir.) y MARTíNEZ SANZ, José Luis (coord.), El comienzo de la Guerra de la Independencia. Congreso Internacional del Bicentenario, Editorial Actas, Madrid, pp. 773-798.

FERNÁNDEZ GARCÍA, Elena (2009b), Mujeres en la Guerra de la Independencia, Sílex, Madrid.

FERNÁNDEZ GARCÍA, Elena (2010), "Mujer y guerra. Un breve balance historiográfico", en VIGUERA, Rebeca (ed.), Dos siglos de historia: actualidad y debate histórico en torno a la Guerra de la Independencia (1808. 1814), Universidad de la Rioja, Logroño, pp. 195-210.

FERNÁNDEZ GARCÍA, Elena (201 la), "Historia y memoria de las mujeres asediadas", Cuestiones de género: de la igualdad y la diferencia, $\mathrm{n}^{\circ} 6$, pp. 35-50.

FERNÁNDEZ GARCÍA, Elena (2011b), "Mujeres sitiadas. La compañía de Santa Bárbara de Girona", Dossiers Feministes, n 15, pp. 63-75.

FREIRE, Ana María (2013), "La imagen de los personajes históricos de la Guerra de la Independencia en la literatura dramática del siglo XIX", Historia y Política, $n^{\circ} 29$, pp. 75-101.

FUENTES, Juan Francisco (2013), "Conceptos previos: Patria y nación en los orígenes de la España contemporánea", en MORALES MOYA, Antonio, FUSÍ, Juan Pablo y DE BLAS, Andrés (dirs.), Historia de la nación y del nacionalismo español, Galaxia Gutemberg, Barcelona, pp. 169-196.

GARCÍA CÁRCEL, Ricardo (2007), El sueño de la nación indomable. Los mitos de la Guerra de la Independencia, Temas de Hoy, Madrid.

GARCÍA CÁRCEL, Ricardo (2010), "Los mitos de la Guerra de la Indepen- 
dencia", en BORREGUERO, Cristina, La Guerra de la Independencia en el mosaico peninsular (1808-1814), Universidad de Burgos, Burgos, pp. 21-46.

HERRERO, José Vicente (2001), "La guerra de fortalezas en el periodo napoleónico (1796-1815)", Revista de Historia Militar, n 91, pp. 129-158. HOCQUELLET, Richard (2008), Resistencia y revolución durante la Guerra de la Independencia. Del levantamiento patriótico a la soberanía nacional, Prensas Universitarias de Zaragoza, Zaragoza.

HOCQUELLET, Richard y MICHONNEAU, Stéphane (2008), "Le héros de guerre, le militaire et la nation", Mélanges de la Casa de Velázquez, $\mathrm{n}^{\circ}$ 38:1, pp. 95-114.

HOWARD, Michael (2009), War in European History, Oxford University Press, Oxford.

JIMÉNEZ, Ana María (2005), "«Los otros combatientes» en la Guerra de la Independencia: el papel femenino", en CASTAÑEDA, Paulino (coord.), Las Guerras en el primer tercio del siglo XIX en España y América. XII Jornadas Nacionales de Historia Militar, tomo II, Deimos, Madrid, pp. 347-365.

KEEGAN, John (2014), Historia de la guerra, Turner, Madrid.

LAFOZ, Herminio (1992), José de Palafox y su tiempo, Diputación General de Aragón, Zaragoza.

LAFOZ, Herminio (1996), La Guerra de la Independencia en Aragón: del Motín de Aranjuez a la capitulación de Zaragoza (marzo 1808-febrero 1809), Institución Fernando el Católico, Zaragoza.

LASPRA, Alicia (2010), La Guerra de la independencia en los archivos británicos del "War Office": colección documental, Ministerio de Defensa, Madrid.

LEJEUNE, Louis-François (2009), Los Sitios de Zaragoza. Historia y pintura de los acontecimientos que tuvieron lugar en esta ciudad abierta durante los dos sitios que sostuvo en 1808 y 1809 , Edición de Pedro Rújula, Institución Fernando el Católico, Zaragoza.

LEVY Darline G. y APPLEWHITE, Harriet B. (1992), "Women and Militant Citizenship on Revolutionary Paris", en MELZER, Sara E. y KABINE, Leslie W (eds.), Rebel Daughters: Women and the French Revolution, Oxford University Press, Nueva York, pp. 79-101.

LÓPEZ VELA, Roberto (2004), "De Numancia a Zaragoza. La construcción del pasado nacional en las historias de España del ochocientos", en GARCÍA CÁRCEL, Ricardo (coord.), La construcción de las Historias de España, Fundación Carolina/Marcial Pons, Madrid, pp. 195-298. 
LYNN, John A. (2008), Women, Armies, and Warfare in Early Modern Europe, Cambridge University Press, Cambridge.

MARÍN ARRUEGO, Nuria (1999), La Condesa de Bureta, Comuniter, Zaragoza.

MARÍN ARRUEGO, Nuria (2009), Mujeres. Los Sitios de Zaragoza, Fundación Zaragoza 2008, Zaragoza.

MARTÍNEZ ÁlVAREZ, Josefina (2010), "La pervivencia de los mitos: la Guerra de la Independencia en el cine", Cuadernos de Historia Moderna. Anejos, n' IX, pp. 191-213.

MARTÍNEZ RUIZ, Enrique (2008a), "La Guerra de la Independencia española: planteamiento nacional y repercusión internacional", Monte Buciero 13. Cantabria durante la Guerra de la Independencia, Santander, pp. 17-43.

MARTÍNEZ RUIZ, Enrique (2008b), "La Guerra de la Independencia española (1808-1814): planteamiento y características de la crisis", Revista General de Marina, tomo 255, pp. 189-199.

MEDINA, Carlos J. (2009), "La artillería en la Guerra de la Independencia", Revista de Historia Militar, n extraordinario "La Guerra de la Independencia. Una visión militar», pp. 281-317.

MORENO ALONSO, Manuel (2008), "Prólogo", en PALAFOX, José de, Autobiografía, Ediciones Espuela de Plata, Sevilla, pp. 9-34.

MORENO LUZÓN, Javier (2004), "Entre el progreso y la virgen del Pilar. La pugna por la memoria en el centenario de la Guerra de la Independencia", Historia y Política, n 12, pp. 41-78.

NASH, Mary y TAVERA, Susana (2003), Las mujeres y las guerras, el papel de las mujeres en las guerras de la Edad Antigua a la Contemporánea, Icaria, Barcelona.

PALAFOX, José de (1994), Memorias, ed. de Herminio Lafoz Rabaza, Rolde de Estudios Aragoneses / Ayuntamiento de Zaragoza, Zaragoza.

PEIRÓ, Antonio (2017), El golpe de Estado del general Palafox, Prensas universitarias de Zaragoza, Zaragoza.

PERLA, José Luis (2009), "Estudio militar de la salida de Palafox de Zaragoza el día 4 de agosto de 1808", en VV.AA., La Guerra de la Independencia Española: una visión militar. Actas del VI Congreso de Historia Militar, vol. II, Ministerio de Defensa, Madrid, pp. 139-150.

QUERALT, María Pilar (2005), "Agustina de Aragón: entre la historia y el mito", Criaturas Saturnianas, n 3, pp. 25-35.

QUERALT, María Pilar (2008), Agustina de Aragón. La mujer y el mito, La Esfera de los Libros, Madrid. 
REYERO, Carlos (2008), "Visiones de la nación en lucha. Escenarios y acciones del pueblo y los héroes", en ÁlVAREZ BARRIENTOS, Joaquín (ed.), La Guerra de la Independencia en la cultura española, Siglo XXI, Madrid, pp. 105-129.

ROMEO, María Cruz (2006), "Destinos de mujer: esfera pública y políticos liberales", en MORANT, Isabel (dir.), Historia de las mujeres en España y América Latina, vol. 3, Cátedra, Madrid, pp. 61-83.

ROMERO, Leonardo (2009), "Los «Sitios de Zaragoza», tema literario internacional (1808-1814)", en DE DIEGO, Emilio (dir.) y MARTíNEZ SANZ, José Luis (coord.), El comienzo de la Guerra de la Independencia. Congreso Internacional del Bicentenario, Edirorial Actas, Madrid, pp. 571-588.

RUDORFF, Raymond (1977), Los Sitios de Zaragoza (1808-1809), Grijalbo, Barcelona.

RÚJULA, Pedro (1994), "Prólogo", en PALAFOX, José de, Memorias, edición de Herminio Lafoz, Rolde de Estudios Aragoneses / Ayuntamiento de Zaragoza, Zaragoza, pp. 9-14.

RÚJULA, Pedro (2009), "Guerra civil y pueblo en armas en los orígenes de la Guerra de la Independencia", en VV. AA., La Guerra de la Independencia Española: una visión militar. Actas del VI Congreso de Historia Militar, vol. I, Ministerio de Defensa, Madrid, pp. 43-52.

RÚJULA, Pedro (2012), "Zaragoza (1808-1809). El mito de la resistencia popular", en BUTRÓN, Gonzalo y RÚJULA, Pedro (eds.), Los sitios en la Guerra de la Independencia: la lucha en las ciudades, Sílex/Universidad de Cádiz, Madrid/Cádiz, pp. 15-37.

SALAS, María Pilar (2007), Descripción bibliográfica de los textos literarios relativos a los Sitios de Zaragoza, Institución Fernando el Católico, Zaragoza. SÁNCHEZ ARRESEIGOR, Juan José (2008), "Mujeres en la guerra", en MIRANDA, Francisco (coord.), Guerra, sociedad y política (1808-1814), vol. I, Universidad Pública de Navarra/Gobierno de Navarra, Pamplona, pp. 691-721.

SANTACARA, Carlos (2005), La Guerra de Independencia vista por los británicos (1808-1814), A. Machado Libros, Madrid.

SERRANO, Eliseo (2010), "Patriotas, héroes y vasallos. La Guerra de la Independencia en Aragón", en BORREGUERO, Cristina (coord.), La Guerra de la Independencia en el mosaico peninsular (1808-1814), Universidad de Burgos, Burgos, pp. 143-169.

TONE, John L. (1999), "Spanish Women in the Resistance to Napoleon 1808-1814", en ENDERS, Victoria Lorée y RADCLIFF, Pamela Beth (eds.), Constructing Spanish Womanhood. Female Identity in Modern Spain, State University of New York Press, Nueva York, pp. 259-282. 
UCELAY DA CAL, Enric (2009), "Agustina, la dama del cañón: el topos de la heroína fálica y el invento de patriotismo", en CASTELLS, Irene, ESPIGADO, Gloria y ROMEO, María Cruz (coords.), Heroínas y patriotas. Mujeres de 1808, Cátedra, Madrid, pp. 193-265.

YUVAL-DAVIS, Nira (1997), Gender \& Nation, Sage Publications, Londres. 